\title{
Antiepileptic drugs prescribed in pregnancy and prevalence of major congenital malformations: comparative prevalence studies
}

This article was published in the following Dove Press journal:

Clinical Epidemiology

16 February 2017

Number of times this article has been viewed

\author{
Irene Petersen ${ }^{1,2}$ \\ Shuk-Li Collings ${ }^{1,3}$ \\ Rachel L McCrea' \\ Irwin Nazareth' \\ David P Osborn ${ }^{4}$ \\ Phil J Cowen ${ }^{5}$ \\ Cormac J Sammon' \\ 'Department of Primary Care and \\ Population Health, University College \\ London, London, UK; ${ }^{2}$ Department \\ of Clinical Epidemiology, Aarhus \\ University, Aarhus N, Denmark; \\ ${ }^{3}$ OXON Epidemiology, London, UK; \\ ${ }^{4}$ Division of Psychiatry, University \\ College London, London, UK; \\ ${ }^{5}$ University Department of Psychiatry, \\ Warneford Hospital, Oxford, UK
}

Correspondence: Irene Petersen Department of Primary Care and Population Health, University College London, Rowland Hill Street, London NW3 2PF, UK

Email i.petersen@ucl.ac.uk
Objective: The aim of this study was to examine the prevalence of major congenital malformations associated with antiepileptic drug (AED) treatment in pregnancy.

Patients and methods: Using data from The Health Improvement Network, we identified women who have given live birth and their offspring. Four subgroups were selected based on the AED treatment in early pregnancy, valproate, carbamazepine, lamotrigine and women not receiving AED treatment. We compared the prevalence of major congenital malformations within children of these four groups and estimated prevalence ratios (PRs) using Poisson regression adjusted for maternal age, sex of child, quintiles of Townsend deprivation score and indication for treatment.

Results: In total, 240,071 women were included in the study. A total of 229 women were prescribed valproate in pregnancy, 357 were prescribed lamotrigine and 334 were prescribed carbamazepine and 239,151 women were not prescribed AEDs. Fifteen out of $229(6.6 \%)$ women prescribed valproate gave birth to a child with a major congenital malformation. The figures for lamotrigine, carbamazepine and women not prescribed AEDs were 2.7\%, 3.3\% and 2.2\%, respectively. The prevalence of major congenital malformation was similar for women prescribed lamotrigine or carbamazepine compared to women with no AED treatment in pregnancy. For women prescribed valproate in polytherapy, the prevalence was fourfold higher. After adjustments, the effect of estimates attenuated, but the prevalence remained two- to threefold higher in women prescribed valproate.

Conclusion: The results of our study suggest that lamotrigine and carbamazepine are safer treatment options than valproate in pregnancy and should be considered as alternative treatment options for women of childbearing potential and in pregnancy.

Keywords: pregnancy, valproate, lamotrigine, carbamazepine, adverse drug effects

\section{Introduction}

There have for some time been concerns as to whether certain antiepileptic medications, in particular valproate, may increase the risks of major congenital malformations. ${ }^{1-6}$ Recently, the guidance on treatment with valproate was strengthened, and doctors in the European Union are now advised not to prescribe valproate for epilepsy or bipolar disorder to women of childbearing age and in pregnancy. ${ }^{7,8}$

While these concerns may have led many women to discontinue treatment either before or in early pregnancy, ${ }^{9}$ a number of women are still in need of antiepileptic drug (AED) treatment during pregnancy, regardless of whether this is for epilepsy or mental illnesses. Thus, women have to consider their own health as well as that of their future child. In some situations, alternative AED treatments may be available 
for women of childbearing potential, but often evidence and guidance remain conflicting in terms of the safety of specific drugs. ${ }^{5,6,10-15}$

Our objective was to estimate and contrast the prevalence of major congenital malformations for the three most commonly used AED treatments, valproate, lamotrigine and carbamazepine ${ }^{9,16}$ during pregnancy in order to examine whether the latter two drugs provide a safer alternative to valproate treatment in pregnancy.

\section{Patients and methods}

We used data from The Health Improvement Network (THIN), a large primary care database that provides anonymized longitudinal general practice (family practice) data on patients' clinical and prescribing records and includes data from $\sim 6 \%$ of the UK population. Diagnoses and symptoms are recorded by practice staff using Read codes, a hierarchical coding system of $>100,000$ codes. ${ }^{17,18}$ The Read code system can be mapped to International Classification of Diseases, 10th revision, but in addition the Read codes include a number of symptom and administrative codes. ${ }^{18}$ Information on weight, height, smoking habits, history of alcohol and illicit drug problems as well as antenatal care and birth details are also recorded. Prescriptions are issued electronically via the general practice computer systems. In addition, the database holds individual patient-level information about year of birth (birth months for individuals younger than 15 years of age), date of registration, dates of death and transfer out of the practice. There is also a household identifier, which is the same for individuals who live in the same household.

Over $98 \%$ of the UK population are registered with a general practitioner (GP, family doctor), ${ }^{19}$ and the database is broadly representative of the UK population..$^{20,21}$ However, Blak et $\mathrm{al}^{20}$ demonstrated that THIN contained slightly more patients who lived in the most affluent areas. While antenatal care is often shared between general practice staff and midwives, the GP remains responsible for women's general medical care during pregnancy, including prescribing medicines.

In this study, we utilized data from January 1, 1995, or when general practices met data quality standards ${ }^{21-23}$ and up to December 31,2014 , or when practices stopped contributing data to THIN.

Within THIN, we identified a group of pregnant women who gave live birth. These women were identified based on the recorded date of delivery; antenatal records, postnatal care records; the first day of last menstrual period (LMP) and the estimated delivery dates (EDD). A very small proportion ( $1 \%$ ) of the pregnant women were identified from LMP and antenatal records alone. We subsequently linked the pregnant women's clinical records to those of the children with the same household identifier if they were registered with the same general practice within 6 months after the children were born. Start of pregnancy was defined as the first day of LMP or 280 days before delivery if no records suggested a different duration of pregnancy. The sample was then restricted to one randomly chosen pregnancy per woman as pregnancies in the same woman may not be independent. We have used a similar approach in other studies on drug safety in pregnancy. ${ }^{9,16,24,25}$

\section{Treatment groups}

We identified four treatment groups based on the type of AED treatment prescribed 31-105 days after the start of the pregnancy (which covers the critical period for many major congenital malformations): ${ }^{26}$ valproate, carbamazepine, lamotrigine, as well as a group of women not prescribed AED, which contained women with no records of AED treatment in the pregnancy or 28 days prior to LMP. Women who received polytherapy (i.e., more than one AED), which included valproate, were considered to belong to the valproate group and women who received polytherapy, which included carbamazepine and lamotrigine, were considered to belong to the carbamazepine group. This was done in order to make the groups mutually exclusive.

\section{Outcome}

All diagnostic codes for congenital malformations in the records of children linked to the pregnant women were identified using codes from the Read code chapter starting with $\mathrm{P}$ (congenital anomalies). ${ }^{18}$ Those diagnostic codes relating to major congenital malformations were then identified in consultation with a GP (IN) and in accordance with the EUROCAT guide. ${ }^{27}$

\section{Covariates}

We extracted information from the women's electronic health records on age at delivery, calendar year of delivery, obesity, illicit drug use, alcohol problem and smoking status. As illicit drug use, alcohol problems and smoking status are often only recorded once, we considered records made up to 3 years before LMP or in pregnancy. For obesity, we considered individuals with a record of obesity or a body mass index of $\geq 30 \mathrm{~kg} / \mathrm{m}^{2}$, which was recorded in the year before the LMP, but not in pregnancy. Information on the sex of the linked children was also extracted. We also considered treatments with other psychotropic medications including antipsychotics, antidepressants and anxiolytics, but in our initial investigations of the data we found no associations with these treatments and major congenital malformations. 
This is supported by previous research in THIN on these treatments. ${ }^{24,28,29}$ Therefore, we decided to exclude these treatments as potential confounders.

\section{Data analysis}

We tabulated the characteristics of the pregnant women treated with valproate, lamotrigine and carbamazepine and the pregnant women not treated with AEDs. We then calculated the prevalence of major congenital malformations in each treatment group as the number of children with a record of major congenital malformations divided by the total number of children in each of the four groups.

Poisson regression was used to estimate relative prevalence ratios (PRs) comparing the prevalence of major congenital malformations in the children of women in various treatment groups. Estimates of PRs were adjusted for maternal age, sex of child, quintiles of Townsend deprivation score and indication for treatment (which were associated with the outcomes in the univariate analysis).
As a sensitivity analysis, we restricted the samples to those women with a record of epilepsy and repeated the abovementioned analyses.

All data analyses were performed in Stata 14.1.

\section{Ethics}

The scheme for THIN to obtain and provide anonymous patient data was approved by the National Health Service South-East Multicenter Research Ethics Committee (MREC) in 2002, and scientific approval for this study was obtained from Cedigem Strategic Data Medical Research's Scientific Review Committee. As data was anonymized informed consent was not required.

\section{Results}

In total, 240,071 pregnancies were included in the study. There were 229 women prescribed valproate in early pregnancy, 334 prescribed carbamazepine, 357 prescribed lamotrigine and 239,151 not prescribed AEDs (Table 1). The

Table I Characteristics of women in the four treatment cohorts

\begin{tabular}{|c|c|c|c|c|c|c|c|c|}
\hline \multirow[t]{3}{*}{ Characteristics } & \multicolumn{8}{|c|}{ Treatment status in first trimester } \\
\hline & \multicolumn{2}{|c|}{ Valproate } & \multicolumn{2}{|c|}{ Carbamazepine } & \multicolumn{2}{|c|}{ Lamotrigine } & \multicolumn{2}{|c|}{ Not treated with AEDs } \\
\hline & $\mathbf{n}$ & $\%$ & $\mathbf{n}$ & $\%$ & $\mathbf{n}$ & $\%$ & n & $\%$ \\
\hline Total & 229 & 100 & 334 & 100 & 357 & 100 & 239,151 & 100 \\
\hline \multicolumn{9}{|l|}{ Age (years) } \\
\hline Mean (SD) & $30(5.6)$ & - & $31(5.5)$ & - & $30(5.3)$ & - & $31(5.9)$ & - \\
\hline $12-19$ & 7 & 3.1 & 4 & 1.2 & 14 & 3.9 & 9,048 & 3.8 \\
\hline $20-29$ & 94 & 41 & 113 & 33.8 & 147 & 41.2 & 89,162 & 37.3 \\
\hline $30-39$ & 117 & $5 I .1$ & 196 & 58.7 & 188 & 52.7 & 128,333 & 53.7 \\
\hline $40-49$ & 11 & 4.8 & 21 & 6.3 & 8 & 2.2 & 12,608 & 5.3 \\
\hline \multicolumn{9}{|l|}{ Year of delivery } \\
\hline 1995-1999 & 34 & 14.8 & 47 & 14.1 & 7 & 2 & 18,626 & 7.8 \\
\hline 2000-2004 & 65 & 28.4 & 98 & 29.3 & 50 & 14 & 59,706 & 25 \\
\hline 2005-2009 & 78 & 34.1 & 106 & 31.7 & 154 & 43.1 & 86,303 & 36.1 \\
\hline 20I0-20I4 & 52 & 22.7 & 83 & 24.9 & 146 & 40.9 & 74,516 & 31.2 \\
\hline \multicolumn{9}{|l|}{ Lifestyle variables } \\
\hline Obesity & 25 & 10.9 & 35 & 10.5 & 38 & 10.6 & 14,697 & 6.1 \\
\hline Illicit drug use & 9 & 3.9 & II & 3.3 & 5 & 1.4 & $\mathrm{I}, 560$ & 0.7 \\
\hline Alcohol problems & 3 & 1.3 & 5 & 1.5 & 4 & 1.1 & 1,252 & 0.5 \\
\hline Smoker & 69 & 30.1 & 63 & 18.9 & 82 & 23 & 47,069 & 19.7 \\
\hline \multicolumn{9}{|l|}{ Townsend score } \\
\hline I & 31 & 13.5 & 71 & 21.3 & 65 & 18.2 & 54,674 & 22.9 \\
\hline 2 & 29 & 12.7 & 59 & 17.7 & 67 & 18.8 & 46,081 & 19.3 \\
\hline 3 & 38 & 16.6 & 73 & 21.9 & 66 & 18.5 & 48,922 & 20.5 \\
\hline 4 & 66 & 28.8 & 58 & 17.4 & 79 & 22.1 & 45,599 & 19.1 \\
\hline 5 & 55 & 24 & 63 & 18.9 & 62 & 17.4 & 33,739 & 14.1 \\
\hline Missing & 10 & 4.4 & 10 & 3 & 18 & 5 & 10,136 & 4.2 \\
\hline \multicolumn{9}{|l|}{ Indication } \\
\hline Unknown indication & 8 & 3.5 & 17 & 5.1 & 7 & 2 & 219,849 & 91.9 \\
\hline Severe mental illness or depression & 14 & 6.1 & 19 & 5.7 & 6 & 1.7 & 16,458 & 6.9 \\
\hline Epilepsy & 207 & 90.4 & 298 & 89.2 & 344 & 96.4 & 2,844 & 1.2 \\
\hline \multicolumn{9}{|l|}{ Child characteristics } \\
\hline Male & 111 & 48.5 & 186 & 55.7 & 180 & 50.4 & $|22,09|$ & 51.1 \\
\hline
\end{tabular}

Abbreviations: AEDs, antiepileptic drugs; SD, standard deviation. 
mean age of women prescribed valproate and lamotrigine was 30 years compared to 31 years in women not prescribed AEDs and women prescribed carbamazepine. For valproate and carbamazepine, $90 \%$ had a record of epilepsy and $6 \%$ had a record of severe mental illnesses (schizophrenia or bipolar disorder) or depression, while $96 \%$ of the women prescribed lamotrigine had a record of epilepsy and $2 \%$ had a record of severe mental illnesses or depression (Table 1). A larger proportion of women prescribed valproate, carbamazepine and lamotrigine had records of illicit drug use (1.4\%-3.9\%), alcohol problems $(1.1 \%-1.5 \%)$ and obesity $(10.5 \%-10.9 \%)$ than women not prescribed AED treatment (Table 1). More women among the valproate treatment group were smokers $(30 \%)$ than the other groups $(19 \%-23 \%)$. Fewer boys than girls $(48.5 \%)$ were born to women who were treated with valproate, whereas more boys than girls were born to women prescribed carbamazepine $(55.7 \%)$ or lamotrigine $(50.4 \%)$ and women not prescribed AEDs (51.1\%; Table 1). The commonest major congenital malformations were cardiovascular malformations including ventricular septal defect and atrial septal defect. Other common malformations include hypospadias and cleft palate (Table S1).

Fifteen $(6.6 \%)$ women prescribed valproate in pregnancy gave birth to a child with a major congenital malformation in comparison to eleven (3.3\%) women prescribed carbamazepine and ten $(2.8 \%)$ women prescribed lamotrigine and $5,315(2.2 \%)$ of women not prescribed AEDs. Finally, five $(9.4 \%)$ women prescribed valproate in polytherapy gave birth to a child with a major congenital malformation.

There was no increased prevalence of major congenital malformation among children of women prescribed carbamazepine or lamotrigine in comparison to women not receiving AEDs (Table 2). In contrast, children of women prescribed valproate in pregnancy had a nearly threefold increased prevalence of major congenital malformation in comparison to women not receiving AEDs. For women prescribed valproate in polytherapy, the prevalence was fourfold higher (Table 2). After adjustments for maternal age, indication for treatment, social deprivation and sex of child, the prevalence associated with valproate attenuated, but was still two to threefold higher in women prescribed valproate (all valproate vs not treated with AED: adjusted PR $\left[\mathrm{PR}_{\text {adj }}\right] 2.19 ; 95 \%$ confidence interval (CI): 1.32-3.64; polytherapy valproate vs not treated with AED: PR $_{\text {adj }} 2.98 ; 95 \%$ CI: $1.29-6.88$; Table 2). Although the prevalence of obesity, illicit drug use, alcohol problems and smoking varied among the four treatment groups, there were no associations between these and the prevalence of major congenital malformations.

A direct comparison between children of women prescribed valproate and women prescribed lamotrigine/carbamazepine revealed that the adjusted prevalence was twofold higher for valproate ( $\mathrm{PR}_{\text {adj }}$ 2.33; 95\% CI: 1.21-4.50; Table 2).

Restricting the samples to individuals with a record of epilepsy provided similar estimates of prevalence and PRs to the primary analyses (Table 3 ).

\section{Discussion}

The results of our study suggest that the prevalence of major congenital malformations among children of women treated with carbamazepine or lamotrigine was comparable to the prevalence in women not treated with AEDs. However, we found a two- to threefold increased prevalence of major congenital malformations among children of women treated with valproate in pregnancy compared to children of women not prescribed AEDs. Similar increased prevalence was observed when comparisons were made between children of women treated with valproate and carbamazepine or lamotrigine. Finally, the prevalence of major congenital malformation

Table 2 Prevalence and results from unadjusted and adjusted analyses of PRs and $95 \% \mathrm{Cls}$ of MCM

\begin{tabular}{|c|c|c|c|c|c|c|c|}
\hline $\begin{array}{l}\text { Comparisons made } \\
\text { between }\end{array}$ & Total (N) & $\operatorname{MCM}(n)$ & $\begin{array}{l}\text { Prevalence per } \\
\text { I } 00 \text { live births }(95 \% \mathrm{Cl})\end{array}$ & $\mathbf{P R}_{\text {unadj }}$ & $95 \% \mathrm{Cl}$ & $\mathbf{P R}_{\mathrm{adj}}^{*}$ & $95 \% \mathrm{Cl}$ \\
\hline No AED & 239,151 & 5,315 & $2.22(2.16-2.28)$ & 1 & - & 1 & - \\
\hline Valproate & 229 & 15 & $6.55(3.7 I-10.57)$ & 2.95 & $(\mathrm{I} .8 \mathrm{I}-4.8 \mathrm{I})$ & 2.19 & $(1.32-3.64)$ \\
\hline No AED & 239,151 & 5,315 & $2.22(2.16-2.28)$ & I & - & I & - \\
\hline Valproate polytherapy & 53 & 5 & $9.43(3.13-20.66)$ & 4.24 & $(1.86-9.69)$ & 2.98 & $(1.29-6.88)$ \\
\hline No AED & 239,151 & 5,315 & $2.22(2.16-2.28)$ & I & - & 1 & - \\
\hline Valproate monotherapy & 176 & 10 & $5.68(2.76-10.20)$ & 2.56 & $(1.40-4.67)$ & 1.94 & $(1.05-3.6 I)$ \\
\hline No AED & 239,151 & 5,315 & $2.22(2.16-2.28)$ & I & - & 1 & - \\
\hline Carbamazepine & 334 & $\mathrm{II}$ & $3.29(1.66-5.82)$ & $\mathrm{I} .48$ & $(0.80-2.74)$ & 1.09 & $(0.57-2.09)$ \\
\hline No AED & 239,151 & 5,315 & $2.22(2.16-2.28)$ & I & - & I & - \\
\hline Lamotrigine & 357 & 10 & $2.80(1.35-5.09)$ & 1.26 & $(0.69-2.31)$ & 0.95 & $(0.5 I-1.79)$ \\
\hline Lamotrigine/carbamazepine & 691 & 21 & $3.04(I .89-4.6 I)$ & 1 & - & 1 & - \\
\hline Valproate & 229 & 15 & $6.55(3.7 \mid-10.57)$ & 2.16 & $(1.15-4.04)$ & 2.33 & $(1.21-4.50)$ \\
\hline
\end{tabular}

Note: *Adjusted analyses include adjustments for maternal age, sex of child, quintiles of Townsend deprivation score and indication for treatment.

Abbreviations: PR, prevalence ratio; $\mathrm{Cl}$, confidence interval; $\mathrm{PR}_{\text {unadj }}$, unadjusted PR; $\mathrm{PR}_{\text {adj; }}$, adjusted PR; $A E D$ s, antiepileptic drugs; $M C M$, major congenital malformations. 
Table 3 Prevalence and results from unadjusted and adjusted analyses of PRs and $95 \% \mathrm{Cl}$ of $\mathrm{MCM}$ in children of women with a record of epilepsy

\begin{tabular}{|c|c|c|c|c|c|c|c|}
\hline $\begin{array}{l}\text { Comparisons made } \\
\text { between }\end{array}$ & Total (N) & $\operatorname{MCM}(n)$ & $\begin{array}{l}\text { Prevalence per } 100 \\
\text { live births }(95 \% \mathrm{Cl})\end{array}$ & $\mathbf{P R}_{\text {unadj }}$ & $95 \% \mathrm{Cl}$ & $\mathbf{P R}_{\text {adj }}$ & $95 \% \mathrm{Cl}$ \\
\hline No AED & 2,844 & 86 & $3.02(2.42-3.73)$ & I & - & 1 & - \\
\hline Valproate & 207 & 15 & $7.25(4.06-11.95)$ & 2.40 & $(1.38-4.14)$ & 2.33 & $(1.34-4.04)$ \\
\hline No AED & 2,844 & 86 & $3.02(2.42-3.73)$ & I & - & 1 & - \\
\hline Valproate polytherapy & 50 & 5 & $10.00(3.25-23.33)$ & 3.31 & $(1.34-8.15)$ & 2.81 & $(1.13-7.01)$ \\
\hline No AED & 2,844 & 86 & $3.02(2.42-3.73)$ & I & - & 1 & - \\
\hline Valproate monotherapy & 157 & 10 & $6.37(3.05-\mid I .7 I)$ & 2.11 & $(1.09-4.05)$ & 2.14 & $(I .11-4.13)$ \\
\hline No AED & 2,844 & 86 & $3.02(2.42-3.73)$ & I & - & 1 & - \\
\hline Carbamazepine & 298 & 10 & $3.36(1.61-6.17)$ & I.II & $(0.58-2.14)$ & 1.09 & $(0.56-2.10)$ \\
\hline No AED & 2,844 & 86 & $3.02(2.42-3.73)$ & 1 & - & 1 & - \\
\hline Lamotrigine & 344 & 9 & $2.61(1.20-4.97)$ & 0.87 & $(0.44-I .72)$ & 0.88 & $(0.44-1.75)$ \\
\hline Lamotrigine/carbamazepine & 642 & 19 & $2.96(1.78-4.62)$ & I & - & 1 & - \\
\hline Valproate & 207 & 15 & $7.25(4.06-11.95)$ & 2.59 & $(1.24-4.82)$ & 2.65 & $(1.32-5.30)$ \\
\hline
\end{tabular}

Abbreviations: PR, prevalence ratio; $\mathrm{Cl}$, confidence interval; $\mathrm{PR}_{\text {unadj }}$, unadjusted PR; $\mathrm{PR}$ adj , adjusted PR; MCM, major congenital malformations; $A E D s$, antiepileptic drugs.

was higher among children of women who were treated with valproate as polytherapy compared to monotherapy.

Our findings are in line with previous studies on valproate demonstrating an increased prevalence of congenital malformations associated with valproate treatment in pregnancy, in particular, for those who received valproate in polytherapy., A recent systematic review suggests the prevalence of major congenital malformations among children of women receiving valproate in monotherapy was as high as $10.93 \%(95 \%$ CI: 8.91 to 13.13$),{ }^{6}$ somewhat higher than our estimates for valproate monotherapy (5.68\%; 95\% CI: 2.76 to 10.20$)$. The same review highlights, however, that there may be a dose effect associated with valproate treatment. ${ }^{6}$

Our estimates of major congenital malformations among children of women receiving lamotrigine $(2.80 \%$; $95 \% \mathrm{CI}$ : 1.35 to 5.09$)$ were similar to the pooled estimate from seven studies (2.31\%; 95\% CI: 1.87 to 2.78$).{ }^{6}$ Mølgaard-Nielsen and Hviid ${ }^{13}$ examined the overall risks associated with the use of newer AEDs in pregnancy using data from Danish population registries and found that major birth defects were diagnosed in 38 of 1,019 infants $(3.7 \%)$ exposed to lamotrigine during the first trimester, but the prevalence was not elevated compared to women not treated with AEDs (adjusted prevalence odds ratios, 1.18; 95\% CI: 0.83 to 1.68). Similar observations were made by Cunnington et $\mathrm{al}^{10}$ based on the data from the International Lamotrigine Pregnancy Registry. However, there has been some debate as to whether lamotrigine exposure in pregnancy is associated with orofacial malformations, due to conflicting evidence. .,6,30,31 $^{2}$

For carbamazepine, a large systematic review identified a prevalence of congenital malformations of 3.3\% (95\% CI: 2.7 to 4.2), ${ }^{11}$ remarkably similar to our findings. Another systematic review found a slightly higher prevalence of $4.93 \%$ (95\% CI:
3.84 to 6.16 ), once they took into account variations between studies. ${ }^{6}$ Jentink et $\mathrm{l}^{11}$ suggested an elevated prevalence of spina bifida in children born to women treated with carbamazepine compared to women not treated with AEDs during pregnancy, but the prevalence associated with carbamazepine was only one-fifth relative to valproate treatment. Other studies have suggested associations between carbamazepine and orofacial malformations, but insufficient data are available to refute or confirm increased prevalence of these specific malformations in children of women treated with carbamazepine. ${ }^{6}$

While we could not identify a difference in the prevalence of major congenital malformations between children of women treated with carbamazepine and lamotrigine, Weston et al's ${ }^{6}$ meta-analysis suggested that major congenital malformation is between $1 \%$ and $2 \%$ higher in children of women receiving carbamazepine compared to children of women receiving lamotrigine. However, the prevalence of major congenital malformations for both carbamazepine and lamotrigine was substantially lower than that for valproate. ${ }^{6}$

We found that the prevalence of major congenital malformations did not vary substantially for lifestyle characteristics such as smoking, alcohol problems, obesity and illicit drug use. However, it is possible that the impact of these characteristics is more specific. For example, previous studies have documented significant associations between obesity and prevalence of congenital heart anomalies. ${ }^{24,32}$ Petersen et $\mathrm{al}^{24}$ also demonstrated associations between history of alcohol problems, illicit drug use and congenital heart anomalies.

\section{Strength and limitations}

The strength of this study is that it includes information from a large group of pregnant women and their offspring where information on drug treatment and pregnancy outcomes 
were recorded prospectively and therefore were not subject to recall bias. We were able to evaluate the prevalence of valproate, carbamazepine and lamotrigine within the same study, and as the results of our findings for valproate are in line with previous research it may bring further validity to our findings regarding lamotrigine and carbamazepine.

One of the limitations of our study is that we were unable to examine the prevalence of specific congenital malformations such as spina bifida and orofacial malformation as such malformations are rare and therefore require very large sample sizes to evaluate prevalence with confidence. ${ }^{33}$

Our study included pregnancies which resulted in live births. Hence, it is possible that we may have underestimated the prevalence of major congenital malformations associated with AED treatment in pregnancy. This would happen if AED treatment in pregnancy leads to increased risk of miscarriage and still birth.

We could not perform a direct validation of the records of congenital malformations in THIN. However, a study on recording of congenital malformations in UK primary care was performed using data on 188 potentially major congenital malformations from the General Practice Research Database (which is similar in structure to THIN). This study was able to verify 160 malformations $(85.1 \%)$ as the malformation indicated by the computerized records ranging from $91.7 \%$ of those cases verified using photocopied medical records and $77.9 \%$ of cases verified using free text. ${ }^{34}$ Furthermore, our prevalence estimate $(2.2 \%)$ in children born to women not treated with AEDs during pregnancy is similar to the estimates from British Isles Network of Congenital Anomaly Registers (BINOCAR). ${ }^{35}$ BINOCAR collated data from six regional registers covering $\sim 36 \%$ of the births in England and Wales. Their latest estimate based on data collected in 2012 was 186 per 10,000 births (equivalent to $1.86 \%$ ). ${ }^{35}$

\section{Clinical implications}

The results of our study support treatment with lamotrigine and carbamazepine in pregnancy as a safer alternative to valproate. However, women and health-care professionals need to strike a balance between effectiveness and safety when considering treatment options bearing in mind that for some women switching to carbamazepine or lamotrigine may not be a suitable treatment option. ${ }^{7}$ Alternative treatment options may be considered in this situation, but limited evidence is available on many AEDs. ${ }^{6}$

\section{Conclusion}

The results of our study suggest that lamotrigine and carbamazepine are safer treatment options than valproate in pregnancy and both should be considered as treatment for women of childbearing potential and in pregnancy.

\section{Acknowledgments}

The study was funded by National Institute for Health Research Health Technology Assessment program (Grant $11 / 35 / 06)$. The funder had no role in the design or conduct of the study. We thank the four women who formed a Lived Experience Advisory Panel for their feedback and input on the study.

\section{Disclosure}

PJC has in the last three years been a paid member of an advisory boards of Lundbeck. CJS has received funding for research from Novartis Vaccines and Diagnostics. IP supervises a PhD student who is sponsored by Novo Nordisk. IN is currently member of the NIHR HTA commissioning board. The other authors report no conflicts of interest in this work.

\section{References}

1. Tomson T, Battino D. Teratogenic effects of antiepileptic drugs. Lancet Neurol. 2012;11(9):803-813.

2. Galbally M, Roberts M, Buist A; Perinatal Psychotropic Review Group. Mood stabilizers in pregnancy: a systematic review. Aust N ZJ Psychiatry. 2010;44(11):967-977.

3. Meador K, Reynolds MW, Crean S, Fahrbach K, Probst C. Pregnancy outcomes in women with epilepsy: a systematic review and metaanalysis of published pregnancy registries and cohorts. Epilepsy Res. 2008;81(1):1-13.

4. Jentink J, Loane MA, Dolk H, et al. Valproic acid monotherapy in pregnancy and major congenital malformations. NEngl JMed. 2010;362(23): 2185-2193.

5. Dolk H, Jentink J, Loane M, Morris J, de Jong-van den Berg LTW; EUROCAT Antiepileptic Drug Working Group. Does lamotrigine use in pregnancy increase orofacial cleft risk relative to other malformations? Neurology. 2008;71(10):714-722.

6. Weston J, Bromley R, Jackson CF, et al. Monotherapy treatment of epilepsy in pregnancy: congenital malformation outcomes in the child. Cochrane Database Syst Rev. 2016;11:CD010224.

7. Tomson T, Marson A, Boon P, et al. Valproate in the treatment of epilepsy in girls and women of childbearing potential. Epilepsia. 2015; 56(7):1006-1019.

8. Medicines and Healthcare Products Regulatory Agency [webpage on the Internet]. Valproate and of Risk of Abnormal Pregnancy Outcomes: New Communication Materials Drug Safety Update - GOV.UK [cited Feb 20, 2016]. Available from: https://www.gov.uk/drug-safetyupdate/valproate-and-of-risk-of-abnormal-pregnancy-outcomes-newcommunication-materials. Accessed December 1, 2016.

9. Man S-L, Petersen I, Thompson M, Nazareth I. Antiepileptic drugs during pregnancy in primary care: a UK population based study. PLoS One. 2012;7(12):e52339.

10. Cunnington $M$, Tennis $P$; International Lamotrigine Pregnancy Registry Scientific Advisory Committee. Lamotrigine and the risk of malformations in pregnancy. Neurology. 2005;64(6):955-960.

11. Jentink J, Dolk H, Loane MA, et al. Intrauterine exposure to carbamazepine and specific congenital malformations: systematic review and case-control study. BMJ. 2010;341:c6581.

12. Nulman I. Carbamazepine in pregnancy. BMJ. 2010;341:c6582.

13. Mølgaard-Nielsen D, Hviid A. Newer-generation antiepileptic drugs and the risk of major birth defects. JAMA. 2011;305(19):1996-2002. 
14. National Institute for Health and Care Excellence (NICE) [webpage on the Internet]. Antenatal and Postnatal Mental Health: Clinical Management and Service Guidance. 2014. Available from: http://guidance.nice. org.uk/CG192. Accessed December 19, 2016.

15. Harden CL, Meador KJ, Pennell PB, et al. Practice parameter update: management issues for women with epilepsy - focus on pregnancy (an evidence-based review): teratogenesis and perinatal outcomes report of the Quality Standards Subcommittee and Therapeutics and Technology Assessment Subcommittee of the American Academy of Neurology and American Epilepsy Society. Neurology. 2009;73(2):133-141.

16. Petersen I, McCrea RL, Sammon CJ, et al. Risks and benefits of psychotropic medication in pregnancy: cohort studies based on UK electronic primary care health records. Health Technol Assess. 2016; 20(23):1-176.

17. Chisholm J. The Read clinical classification. Br Med J. 1990; 300(6732):1092.

18. Davé S, Petersen I. Creating medical and drug code lists to identify cases in primary care databases. Pharmacoepidemiol Drug Saf. 2009;18(8):704-707.

19. Lis Y, Mann RD. The VAMP research multi-purpose database in the UK. J Clin Epidemiol. 1995;48(3):431-443.

20. Blak BT, Thompson M, Dattani H, Bourke A. Generalisability of the health improvement network (THIN) database: demographics, chronic disease prevalence and mortality rates. Inform Prim Care. 2011;19(4):251-255.

21. Williams T, van Staa T, Puri S, Eaton S. Recent advances in the utility and use of the General Practice Research Database as an example of a UK Primary Care Data resource. Ther Adv Drug Saf. 2012;3(2):89-99.

22. Horsfall L, Walters K, Petersen I. Identifying periods of acceptable computer usage in primary care research databases. Pharmacoepidemiol Drug Saf. 2013;22(1):64-69.

23. Maguire A, Blak BT, Thompson M. The importance of defining periods of complete mortality reporting for research using automated data from primary care. Pharmacoepidemiol Drug Saf. 2009;18(1):76-83.

24. Petersen I, Evans SJ, Gilbert R, Marston L, Nazareth I. Selective serotonin reuptake inhibitors and congenital heart anomalies comparative cohort studies of women treated before and during pregnancy and their children. J Clin Psychiatry. 2016;77(1):e36-e42.
25. Petersen I, Gilbert R, Evans S, Ridolfi A, Nazareth I. Oral antibiotic prescribing during pregnancy in primary care: UK population-based study. J Antimicrob Chemother. 2010;65(10):2238-2246.

26. Kumar P, Burton BK. Congenital Malformations: Evidence-Based Evaluation and Management. 1st ed. New York: McGraw-Hill Education/Medical; 2007:408.

27. European Surveillance of Congenital Anomalies [webpage on the Internet]. Complete EUROCAT Guide [cited Jun 14, 2016]. Available from: http://www.eurocat-network.eu/aboutus/datacollection/guidelinesforregistration/guide1_4. Accessed December 19, 2016.

28. Petersen I, Sammon CJ, McCrea RL, et al. Risks associated with antipsychotic treatment in pregnancy: comparative cohort studies based on electronic health records. Schizophr Res. 2016;176(2): 349-356.

29. Ban L, West J, Gibson JE, et al. First trimester exposure to anxiolytic and hypnotic drugs and the risks of major congenital anomalies: a United Kingdom population-based cohort study. PLoS One. 2014; 9(6):e100996.

30. Meador KJ, Penovich P. What is the risk of orofacial clefts from lamotrigine exposure during pregnancy? Neurology. 2008;71(10):706-707.

31. Holmes LB, Baldwin EJ, Smith CR, et al. Increased frequency of isolated cleft palate in infants exposed to lamotrigine during pregnancy. Neurology. 2008;70(Issue 22, pt 2):2152-2158.

32. Mills JL, Troendle J, Conley MR, Carter T, Druschel CM. Maternal obesity and congenital heart defects: a population-based study. Am J Clin Nutr. 2010;91(6):1543-1549.

33. European Surveillance of Congenital Anomalies [webpage on the Internet]. EUROCAT [cited May 18, 2016]. Available from: http://www. eurocat-network.eu/accessprevalencedata/prevalencetables. Accessed December 19, 2016.

34. Charlton RA, Weil JG, Cunnington MC, de Vries CS. Identifying major congenital malformations in the UK general practice research database (GPRD): a study reporting on the sensitivity and added value of photocopied medical records and free text in the GPRD. Drug Saf. 2010; 33(9):741-750.

35. Springett A, Budd J, Draper ES, et al. Congenital Anomaly Statistics 2012. England and Wales; London: British Isles Network of Congenital Anomaly Registers; 2014. 


\section{Supplementary material}

Table SI The 50 most commonly recorded Read codes for major congenital malformations

\begin{tabular}{|c|c|}
\hline Read codes & Description \\
\hline P54..00 & Ventricular septal defect \\
\hline PC60.00 & Hypospadias \\
\hline PA5..00 & Congenital hypertrophic pyloric stenosis \\
\hline P550.00 & Atrial septal defect NOS \\
\hline P90..00 & Cleft palate \\
\hline PD23.II & Congenital dilated renal pelvis \\
\hline PEI..12 & Sternomastoid tumor \\
\hline P7I..00 & Coarctation of aorta \\
\hline PD34.II & Duplex kidneys \\
\hline P52..00 & Tetralogy of Fallot \\
\hline PF0..00 & Polydactyly - supernumerary digits \\
\hline PG0y000 & Brachycephaly \\
\hline P92..00 & Cleft palate with cleft lip \\
\hline PD23.00 & Congenital hydronephrosis \\
\hline P55..00 & Ostium secundum atrial septal defect \\
\hline PG0z.II & Dysmorphic features \\
\hline PB26.00 & Imperforate anus \\
\hline PFI..00 & Syndactyly - webbing of digits \\
\hline PG7I.00 & Gastroschisis \\
\hline P6y2.00 & Pulmonary infundibular stenosis \\
\hline PB30.00 & Hirschsprung's disease \\
\hline PC33.00 & Bicornuate uterus \\
\hline PFI3.II & Webbed toes \\
\hline$P 9 \ldots 00$ & Cleft palate and lip \\
\hline PFOI.00 & Accessory fingers \\
\hline $\mathrm{P} 21 . .00$ & Microcephalus \\
\hline P91..00 & Cleft lip (harelip) \\
\hline PDII.00 & Polycystic kidney disease \\
\hline P360.00 & Congenital ptosis \\
\hline PG03.00 & Craniosynostosis \\
\hline $\mathrm{PI} \ldots 00$ & Spina bifida \\
\hline PD02.00 & Congenital absence of kidney \\
\hline PG0C.00 & Pierre-Robin syndrome \\
\hline PDI3.II & Multicystic kidney \\
\hline P6z..00 & Congenital heart anomaly NOS \\
\hline $\mathrm{PH} 3 y 200$ & Epidermolysis bullosa \\
\hline P5I..00 & Transposition of great vessels \\
\hline PKy9300 & Prader-Willi syndrome \\
\hline P641.00 & Bicuspid aortic valve \\
\hline P67..00 & Hypoplastic left heart syndrome \\
\hline$P 602.00$ & Congenital pulmonary stenosis \\
\hline PK5..00 & Tuberous sclerosis \\
\hline P31..00 & Microphthalmos \\
\hline P63..00 & Congenital aortic valve stenosis \\
\hline PHI..00 & Ichthyosis congenital \\
\hline P344200 & Coloboma of iris \\
\hline P3y0.00 & Ocular albinism \\
\hline P80..00 & Choanal atresia \\
\hline PA30.00 & Atresia of esophagus \\
\hline PC603I2 & Hypospadias, glandular \\
\hline
\end{tabular}

Abbreviation: NOS, not otherwise specified. 
Clinical Epidemiology is an international, peer-reviewed, open access, online journal focusing on disease and drug epidemiology, identification of risk factors and screening procedures to develop optimal preventative initiatives and programs. Specific topics include: diagnosis, prognosis, treatment, screening, prevention, risk factor modification,

Submit your manuscript here: https://www.dovepress.com/clinical-epidemiology-journal
Dovepress

systematic reviews, risk and safety of medical interventions, epidemiology and biostatistical methods, and evaluation of guidelines, translational medicine, health policies and economic evaluations. The manuscript management system is completely online and includes a very quick and fair peer-review system, which is all easy to use. 